Application note

\title{
Potential of a terrestrial LiDAR-based system to characterise weed vegetation in maize crops
}

\author{
Dionisio Andújar ${ }^{\mathrm{a}}$, Alexandre Escolà ${ }^{\mathrm{b}}$, Joan R. Rosell-Polo ${ }^{\mathrm{b}}$, César Fernández-Quintanilla ${ }^{\mathrm{a}}$, \\ José Dorado ${ }^{\mathrm{a}, *}$ \\ anstituto de Ciencias Agrarias, CSIC, Serrano 115 B, 28006 Madrid, Spain \\ ${ }^{\mathrm{b}}$ Departament d'Enginyeria Agroforestal, Universitat de Lleida, Av. Rovira Roure 191, 25198 Lleida, Spain
}

\section{A R T I C L E I N F O}

\section{Article history:}

Received 27 April 2012

Received in revised form 18 December 2012

Accepted 19 December 2012

\section{Keywords:}

LiDAR technology

Precision crop protection

Site-specific weed management

Weed discrimination

\begin{abstract}
A B S T R A C T
LiDAR (Light Detection And Ranging) is a remote-sensing technique for the measurement of the distance between the sensor and a target. A LiDAR-based detection procedure was tested for characterisation of the weed vegetation present in the inter-row area of a maize field. This procedure was based on the hypothesis that weed species with different heights can be precisely detected and discriminated using non-contact ranging sensors such as LiDAR. The sensor was placed in the front of an all-terrain vehicle, scanning downwards in a vertical plane, perpendicular to the ground, in order to detect the profile of the vegetation (crop and weeds) above the ground. Measurements were taken on a maize field on $3 \mathrm{~m}$ wide $\left(0.45 \mathrm{~m}^{2}\right)$ plots at the time of post-emergence herbicide treatments. Four replications were assessed for each of the four major weed species: Sorghum halepense, Cyperus rotundus, Datura ferox and Xanthium strumarium. The sensor readings were correlated with actual, manually determined, height values $\left(r^{2}=0.88\right)$. With canonical discriminant analysis the high capabilities of the system to discriminate tall weeds (S. halepense) from shorter ones were quantified. The classification table showed $77.7 \%$ of the original grouped cases (i.e., 4800 sampling units) correctly classified for S. halepense. These results indicate that LiDAR sensors are a promising tool for weed detection and discrimination, presenting significant advantages over other types of non-contact ranging sensors such as a higher sampling resolution and its ability to scan at high sampling rates.
\end{abstract}

(c) 2013 Elsevier B.V. All rights reserved.

\section{Introduction}

In spite of the fact that weed detection technologies have been widely explored, the commercial uptake of these technologies has been very limited. Relatively simple optoelectronic sensors have been used for weed mapping or patch spraying in noncultivated areas and in row crops (Biller, 1998; Andújar et al., 2011a). However, these sensors are not able to discriminate between different weed species, limiting their use to broad-spectrum herbicide treatments. Numerous studies have shown the possibility to discriminate different plant species based on their shape, texture and colour using vision technologies (Slaughter et al., 2008; Weis and Sökefeld, 2010; Rumpf et al., 2012). Although these technologies are accurate when weeds are small, their accuracies are significantly reduced when plants get larger and their leaves start to overlap. Ultrasonic sensors have been devised to characterise crop canopies, detecting structural differences in the vertical distribution of crop leaves (Shibayama et al., 1985). Recent studies con-

\footnotetext{
* Corresponding author.

E-mail address: jose.dorado@ica.csic.es (J. Dorado).
}

ducted with these types of sensors have showed their potential for the automatic discrimination between various monocotyledonous and dicotyledonous weeds based on height differences (Andújar et al., 2011b). The use of these low-cost, fast-response sensors provides an interesting opportunity for real-time spraying of row crops when the weed types to be identified have different sizes. However, this technology has some limitations: (a) the scanned area (surface area explored) of these sensors is relatively small (20-50 cm, corresponding to the footprint of a single sensor); consequently, a large number of sensors would be needed to scan a representative portion of the field; (b) because of this reduced scanned area, the measurements do not include the crop row area; and (c) ultrasonic sensors are not able to discriminate crop leaves that invade the scanned area in the inter-row space, leading to false positives. In this regard, a higher spatial and temporal sampling sensor could provide information on the crop row location and on the weed height in the inter-row area. LiDAR sensing technologies have been used in some agricultural and forestry applications, such as robotic guidance (Subramanian et al., 2006), estimation of cereal crop volume (Saeys et al., 2009) and electronic measurement of canopy dimensions in woody crops (Richardson 
et al., 2009; Llorens et al., 2011; Rosell and Sanz, 2012). The capabilities of this type of devices to remotely detect objects and estimate distances, and its wider scanning area make them very appropriate to detect and discriminate weeds in row crops. This work assesses the usage of LiDAR for scanning ground vegetation in maize fields, analysing its capabilities for row-crop identification and its possibilities for weed species discrimination at the time of applying post-emergence herbicides.

\section{Materials and methods}

\subsection{LiDAR sampling system}

A Terrestrial Laser Scanner (TLS) sensor based on phase shift LiDAR technology was used to estimate vegetation height. This sensor provides non-contact measurement of the distance between the TLS and the object of interest. The sensor used was a Hokuyo URG-04LX phase shift TLS. The LiDAR sensor contains a source of laser light (whose intensity is modulated according to a sinusoidal signal of a certain frequency) and a photodetector to detect the reflected beam from the object of interest. The distance between the object and the sensor is determined from the measured phase shift between the emitted light beam and the object's reflected beam detected by the photodetector. Possible distance ambiguities are filtered by the sensor. The sensor estimates the distance to different points of the object of interest by modifying the direction of the emitted laser beam by means of a rotating mirror which deflects the beam in different directions within the same plane. Thus, the sensor performs an angular scanning of the object within a plane, obtaining the distances from a set of object points in the measurement plane as a result. Finally, moving the sensor in the direction perpendicular to the scanning plane, distances to object points situated in adjacent planes are obtained, to cover the whole object of interest.

The sensor was fixed in a metal frame scanning downwards in a vertical plane perpendicular both to the ground and the travel direction in order to detect the vegetation profile above the ground. The divergence of the laser beam emitted by the TLS results in a certain footprint when impacting an object. In our study, the sensor was located $1.5 \mathrm{~m}$ in height and, according to the manufacturer's technical specifications, the corresponding laser beam diameter in the measurement range was $15 \mathrm{~mm}$. This laser beam footprint may contain ground, crop, weeds or mixtures of them. The frame supporting the TLS was fixed to the front of an All Terrain Vehicle (Fig. 1). The software required to acquire and process the LiDAR readings was developed using LabVIEW ${ }^{\circledR}$ (National Instruments) graphical development environment.

\subsection{Study site and procedure}

The study was conducted in a maize field at La Poveda Research Farm (Arganda del Rey, Madrid, Spain). Maize was planted with $75 \mathrm{~cm}$ row spacing and a density of 90,000 plants ha $^{-1}$. Natural weed infestations were composed of two dicotyledonous (Datura ferox L. and Xanthium strumarium L.) and two monocotyledonous weeds, Cyperus rotundus L. (Cyperaceae) and Sorghum halepense (L.) Pers. (Poaceae). Weeds were assessed on May 13 at maize growth stage $\mathrm{BBCH} 12-14(16.0 \pm 3.0 \mathrm{~cm}$ height). Weed growth stages were $\mathrm{BBCH} 14$ (D. ferox, $6.5 \pm 2.5 \mathrm{~cm}$ height), $\mathrm{BBCH} 16$ (X. strumarium, $9.0 \pm 5.0 \mathrm{~cm}$ height; and $C$. rotundus, $9.0 \pm 3.5 \mathrm{~cm}$ height) and $\mathrm{BBCH} 24$ ( $S$. halepense, $17.0 \pm 10.0 \mathrm{~cm}$ height).

Based on the differential distribution of the various weed species in the field ('weed patches'), four plots of $0.45 \mathrm{~m}^{2}(300 \mathrm{~cm}$ wide $\times 15 \mathrm{~cm}$ ) were located (as randomly as possible) in patches where each species was dominant (accounting for more than $75 \%$ of total weed density). Plants from the other weed species were removed manually. Two sets of data were collected on these 16 plots ( 4 species $\times 4$ plots per species). The first, aimed at testing the reliability of the LiDAR system to accurately measure the vegetation height and the soil profile, was obtained in the whole plot. For each $\mathrm{cm}$ of plot width, actual weed height (Va) and LiDAR vegetation height (VL) were computed from vegetation height profiles (see below) for a total of 300 sampling units per plot. Actual ground height $(\mathrm{Ga})$ and LiDAR ground height $(\mathrm{GL})$ were also evaluated in the same way. The actual (Va and Ga) profiles were drawn from digital images while LiDAR profiles were generated by fitting the average line through nine LiDAR repeated measures per plot. A second set of data, which was used to assess the relationship between LiDAR readings and weed density and weed biomass, was obtained by dividing each plot into $12(25 \mathrm{~cm}$ wide $\times 15 \mathrm{~cm})$ sub-plots where weed parameters were taken.

Nine separate LiDAR readings, i.e. nine repeated measures (effective beam footprint of $15 \mathrm{~mm}$ ) were taken from each plot in order to avoid errors from the sensing technique, so that the sensor was positioned vertically to the plot. Afterwards, a panoramic view composed of 4 (75 cm wide) digital images was obtained of each plot, using a Nikon D70 digital camera positioned at a distance of $120 \mathrm{~cm}$ from the plot and at ground level in order to obtain a profile image of the vegetation. The vegetation between the plot and the camera was removed in order to avoid interferences.

A modified version of the pin-microrelief method (Abd Elbasit et al., 2009) was used to measure both plant height and ground surface level from digital images. A vertical metal frame $(300 \mathrm{~cm} \times 60 \mathrm{~cm})$ with 70 movable aluminium rods $4 \mathrm{~cm}$ equidistant from each other as well as a graph paper background with a $\mathrm{cm}$ scale was placed in the back of the plot (Fig. 2). The aluminium rods could move up and down through holes drilled on two lateral metal bands attached to the frame allowing to measure Ga profile, i.e., the baseline. Each aluminium rod had a red mark at the top rim which coincided with a zero elevation line marked on the frame when the frame was placed on a flat surface. In a rough ground surface, the red marks were above the baseline when the rods were supported on an elevated surface and below the baseline when they were on a depression. Hence, Va was determined in digital images by subtracting Ga (shown by the profile of the rods) from the profile of maximum vegetation height.

After taking LiDAR readings and digital images, all plants present in a plot (i.e., belonging to the same weed species) were counted for weed density and collected for dry weight biomass determination, dividing the plot into twelve sub-plots $25 \mathrm{~cm}$ long in the direction perpendicular to rows and $15 \mathrm{~cm}$ wide in the row direction.

Afterwards, in order to obtain the GL profile, nine LiDAR repeated measures were taken on the vegetation-free ground. The VL profile was obtained by subtracting GL to the previous LiDAR readings.

Data were processed using AutoCAD $2012^{\circledR}$ (Autodesk, Inc.). LiDAR measurements were projected and trimmed at the edges so that only the $3 \mathrm{~m}$ corresponding to the plot area were used. Profiles of maximum weed height and ground (VL and GL, respectively) were created using the nine LiDAR repeated measures of each plot. Also, the panoramic view created within each plot with the four digital images, was projected in the same software to manually draw the actual vegetation height and ground profiles (Va and $\mathrm{Ga}$, respectively). Afterwards, data from each centimetre (i.e., 300 sampling units in the $300 \mathrm{~cm}$ long plot) were recorded in the four height profiles in order to obtain a database for point by point comparisons. Additionally, a second set of data was obtained by calculating the average VL height in each $25 \mathrm{~cm}$ sub-plot, so that 12 sampling units per plot were recorded. 


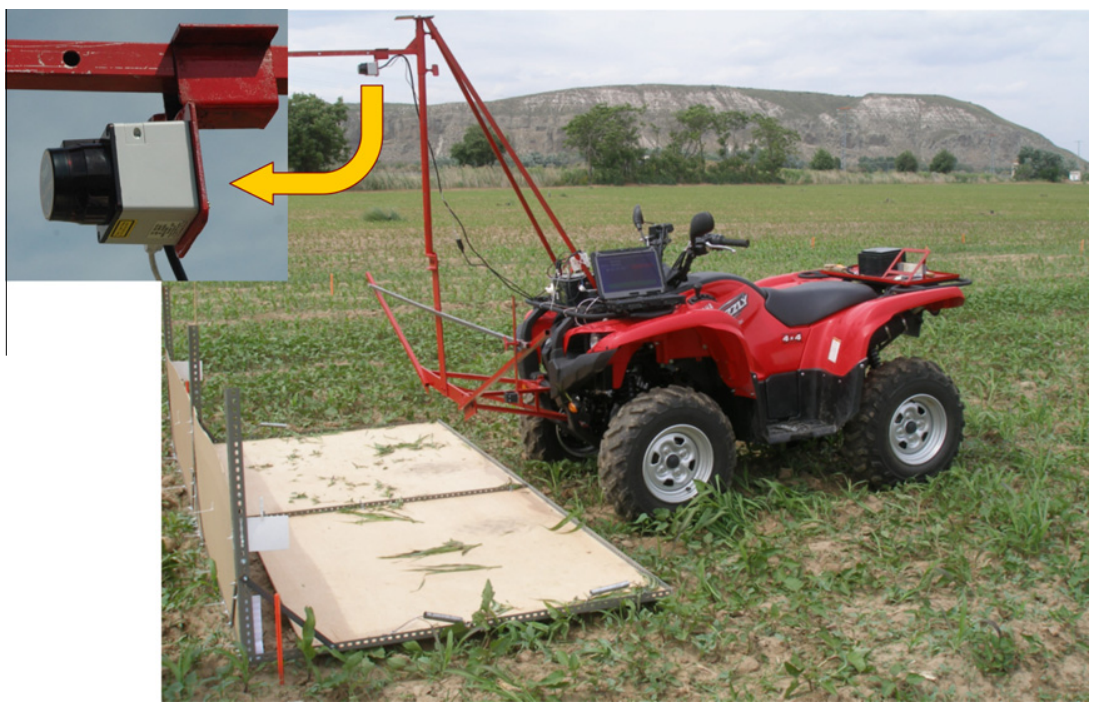

Fig. 1. Image of the ATV with a structure to support the terrestrial LiDAR sensor and the data acquisition system ready to capture height readings from a single plot.

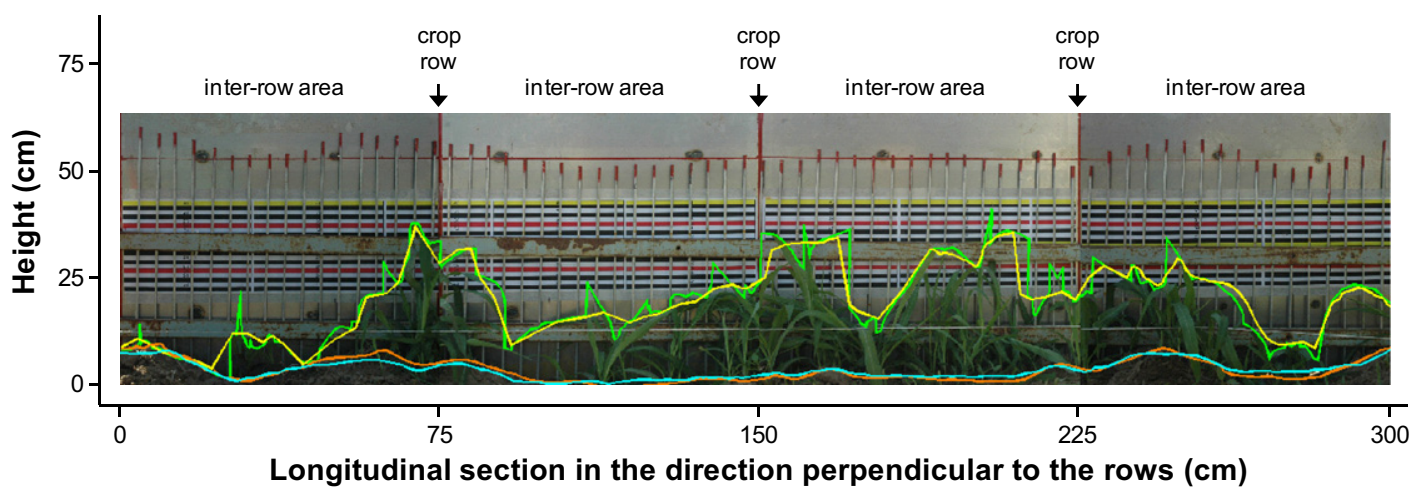

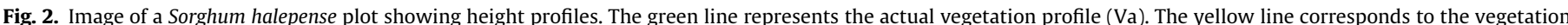

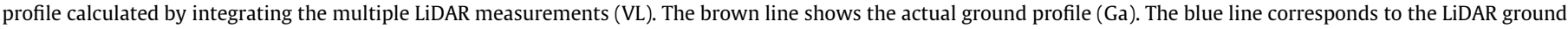
profile (GL). (For interpretation of the references to colour in this figure legend, the reader is referred to the web version of this article.)

\subsection{Statistical analysis}

Before performing a regression analysis, we tested the normal distribution of residuals, as well as the assumptions that residuals had a mean of zero and constant variance (homoscedasticity). Pearson's correlation coefficient was used to analyse simple linear relationships between Va (actual weed heights as predictor/independent variable) and VL (LiDAR measurements as outcome/ dependent variable) using the database with 4800 sampling units (300 per plot) of both profiles. In addition, this database was used to implement a canonical discriminant analysis (CDA) to classify and discriminate the four groups, each of them belonging to a weed species (Kenkel et al., 2002) using the specific Va as interval variables and VL as classification variable. Although we did not observe an overall canonical correlation, a trend was found for S. halepense. Consequently we repeated CDA with only two groups, $S$. halepense and the rest of weed species, to predict whether the individual species can be correctly classified from the rest. Finally, a multiple linear regression analysis was performed to assess the relationship between average LiDAR readings at the $25 \times 15 \mathrm{~cm}$ sub-plots (response variable) and two explanatory variables, weed biomass and weed density, using the database with 192 sampling units (12 per plot). All statistical analyses were performed using SPSS $^{\circledR}$ v19.0 (IBM SPSS Statistics).

\section{Results and discussion}

The measurements obtained with the system showed a high agreement for vegetation and ground profiles. Indeed, Va and VL showed similar patterns, identifying the positions of crop rows, vegetation free areas and weed infested areas (Fig. 2). In addition, Ga and GL also showed high agreement, confirming the potential of this system to measure ground surface topography or micro-topography (Abd Elbasit et al., 2009).

The high correlation between Va and VL heights obtained with the entire database for the four weed species (Fig. $3 ; r^{2}=0.88$ ) showed that LiDAR is a promising tool for the assessment of vegetation height. The results varied for different weed species. Indeed, the height of the short ( $D$. ferox, $6.5 \mathrm{~cm}$ height, $r^{2}=0.48$ ), intermediate (C. rotundus, $9.0 \mathrm{~cm}$ height, $r^{2}=0.55 ; X$. strumarium, $9.0 \mathrm{~cm}$ height, $r^{2}=0.80$ ) and tall species ( $S$. halepense, $17.0 \mathrm{~cm}$ height, $r^{2}=0.86$ ) were correlated to different extents with LiDAR height.

Results of multiple linear regression analysis using the set of data obtained in sub-plots of $25 \times 15 \mathrm{~cm}$ showed weed biomass as the only explanatory variable related with LiDAR readings (i.e., the dependent variable), with coefficients of determination ranging from 0.21 to 0.68 for the different species (Table 1 ). In contrast, weed density was not significantly related to LiDAR readings in any of the weed species studied. 


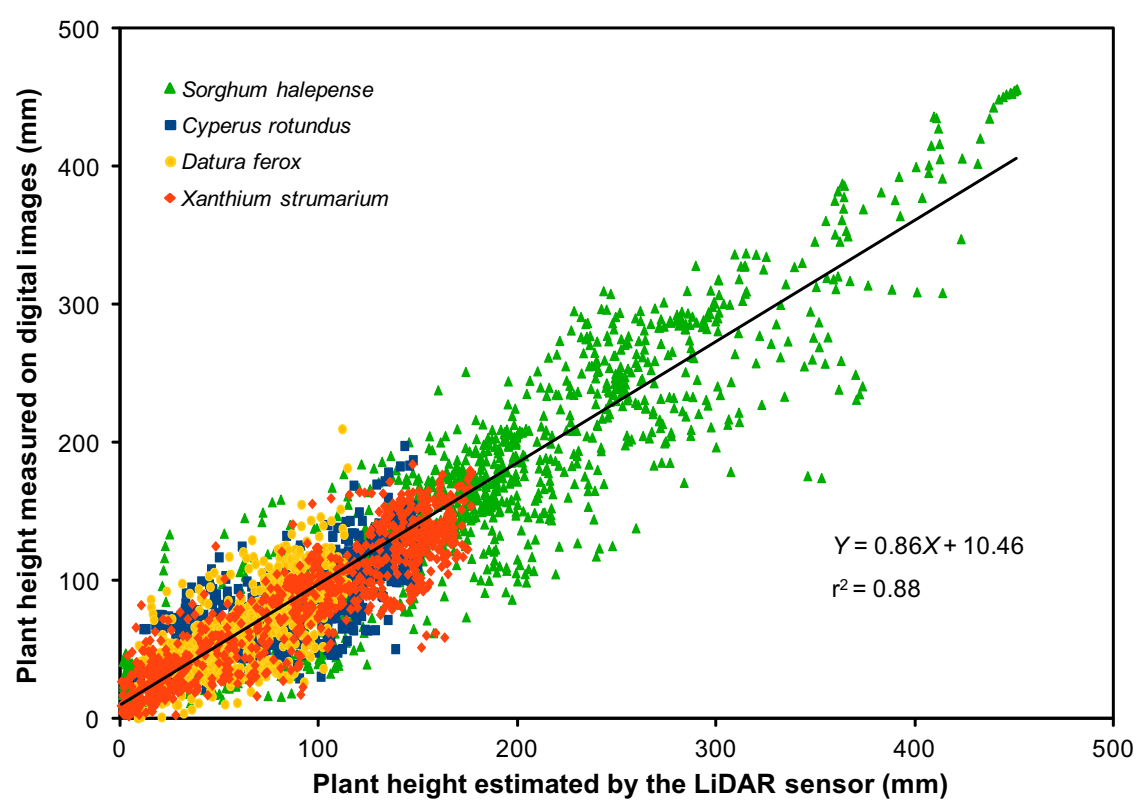

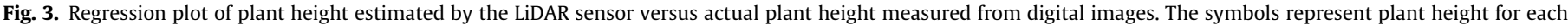
weed species: Sorghum halepense (L.) Pers., Datura ferox L., Xanthium strumarium L. and Cyperus rotundus L.

Table 1

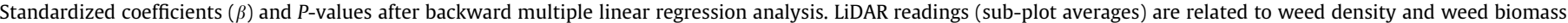
for each species.

\begin{tabular}{|c|c|c|c|c|c|c|c|c|}
\hline & \multicolumn{2}{|c|}{ Sorghum halepense } & \multicolumn{2}{|c|}{ Datura ferox } & \multicolumn{2}{|c|}{ Xanthium strumarium } & \multicolumn{2}{|c|}{ Cyperus rotundus } \\
\hline & $P$ & $\beta$ & $P$ & $\beta$ & $P$ & $\beta$ & $P$ & $\beta$ \\
\hline Constant & $<0.001$ & - & $<0.001$ & - & $<0.001$ & - & $<0.001$ & - \\
\hline Weed biomass & 0.001 & 0.456 & $<0.001$ & 0.729 & $<0.001$ & 0.826 & $<0.001$ & 0.633 \\
\hline Weed density & $-{ }^{a}$ & $-{ }^{a}$ & $-a^{a}$ & $-{ }^{\mathrm{a}}$ & $-^{\mathrm{a}}$ & $-{ }^{a}$ & $-^{\mathrm{a}}$ & $-{ }^{a}$ \\
\hline Sig. & $<0.001$ & & $<0.001$ & & $<0.001$ & & $<0.001$ & \\
\hline$R^{2}$ & & 0.208 & & 0.532 & & 0.682 & & 0.401 \\
\hline
\end{tabular}

a This variable has no significant effect in determining the LiDAR readings of the four weed species.

The CDA showed the capabilities and limitations of the system. When performing a four group (i.e., four weed species) discriminant analysis, canonical functions did not discriminate correctly among groups. However, when CDA analysis was performed using two groups, one for $S$. halepense and one for the other weed species, $77.7 \%$ of the original grouped cases (also $77.7 \%$ of the cross-validated grouped cases) were correctly classified for $S$. halepense. These results agree with those of Fig. 3 showing simple linear relationships, where $S$. halepense points are clearly separated from the others, due to the greater height of these plants. These predictions open the possibility of site-specific treatments against $S$. halepense, one of the most problematic weeds in maize fields in the Mediterranean region (Holm et al., 1977).

Although sensor readings did not allow discriminating the two dicotyledonous species, this does not suppose a major practical problem: these species are generally controlled by the same herbicides. In the case of $C$. rotundus, our results show that it can be easily discriminated from the other monocotyledonous weed ( $S$. halepense) due to its lower size. However, in order to discriminate it from dicotyledonous weeds of similar size it would be necessary to combine LiDAR readings with the results obtained from a sensor based on classification of leaf shapes (Weis and Sökefeld, 2010; Rumpf et al., 2012).

Previous studies have already shown that the different heights of different weed species could be used as a basis for weed discrimination by using ultrasonic sensors (Andújar et al., 2011b). Based on the results of our work, we can conclude that LiDAR sensors can detect weeds in a maize field and discriminate taller $(>18 \mathrm{~cm})$ weeds located within weed patches at the time of herbicide application. In addition, LiDAR sensors offer several advantages over other types of non-contact distance sensors. The larger scanned area of the laser beam and its ability to operate at high speed scanning mode make these sensors ideal to be integrated in on-line operations for site-specific herbicide treatments. Furthermore, LiDAR readings could be used in multi-purpose systems: detection and discrimination of weeds for selective herbicide spraying, crop row identification for automatic guidance and recognition of obstacles for fully automatic vehicle steering. For this latter application, the LiDAR sensor should be mounted to scan in an intermediate plane between vertical and horizontal planes.

\section{Acknowledgement}

This research was funded by the Spanish CICyT (Project AGL 2008-04670-C03).

\section{References}

Abd Elbasit, M.A.M., Anyogi, H., Yasuda, H., Yamamoto, S., 2009. Potential of low cost close-range photogrammetry system in soil microtopography quantification. Hydrological Processes 23, 1408-1417.

Andújar, D., Ribeiro, A., Fernández-Quintanilla, C., Dorado, J., 2011a. Accuracy and feasibility of optoelectronic sensors for weed mapping in row crops. Sensors 11, 2304-2318. 
Andújar, D., Escolà, A., Dorado, J., Fernández-Quintanilla, C., 2011b. Weed discrimination using ultrasonic sensors. Weed Research 51, 543-547.

Biller, R.H., 1998. Reduced input of herbicides by use of optoelectronic sensors. Journal of Agricultural Engineering Research 71, 357-362.

Holm, L.G., Plucknett, D.L., Pancho, J.V., Herberger, J.P., 1977. The Worlds's Worst Weeds. Distribution and biology. University of Hawaii Press, Honolulu, HA.

Kenkel, N.C., Derksen, D.A., Thomas, A.G., Watson, P.R., 2002. Review: multivariate analysis in weed science research. Weed Science 50, 281-292.

Llorens, J., Gil, E., Llop, J., Escolà, A., 2011. Ultrasonic and LiDAR sensors for electronic canopy characterization in vineyards: advances to improve pesticide application methods. Sensors 11, 2177-2194.

Richardson, J.J., Moskal, L.M., Kim, S.-H., 2009. Modeling approaches to estimate effective leaf area index from aerial discrete-return LIDAR. Agricultural and Forest Meteorology 149, 1152-1160.

Rosell, J.R., Sanz, R., 2012. A review of methods and applications of the geometric characterization of tree crops in agricultural activities. Computers and Electronics in Agriculture 81, 124-141.
Rumpf, T., Römer, C., Weis, M., Sökefeld, M., Gerhards, R., Plümer, L., 2012. Sequential support vector machine classification for small-grain weed species discrimination with special regard to Cirsium arvense and Galium aparine. Computers and Electronics in Agriculture 80, 89-96.

Saeys, W., Lenaerts, B., Craessaerts, G., De Baerdemaeker, J., 2009. Estimation of the crop density of small grains using LiDAR sensors. Biosystems Engineering 102, 22-30.

Shibayama, M., Akiyama, T., Munakata, K., 1985. A portable field ultrasonic sensor for crop canopy characterization. Remote Sensing of Environment 18, 269-279.

Slaughter, D.C., Giles, D.K., Downey, D., 2008. Autonomous robotic weed control systems: a review. Computers and Electronics in Agriculture 61, 63-78.

Subramanian, V., Burks, T.F., Arroyo, A.A., 2006. Development of machine vision and laser radar based autonomous vehicle guidance systems for citrus grove navigation. Computers and Electronics in Agriculture 53, 130-143.

Weis, M., Sökefeld, M., 2010. Detection and identification of weeds. In: Oerke, E.C. Gerhards, R., Menz, G., Sikora, R.A. (Eds.), Precision Crop Protection - The Challenge and Use of Heterogeneity. Springer Verlag, Dordrecht, pp. 119-134. 